\title{
Monitoring the Scrovegni Chapel crypt by IR thermography
}

\author{
by Paolo Bison *, Alessandro Bortolin •, Gianluca Cadelano •, Giovanni Ferrarini^, Fabio Peron $\bullet$, \\ Piercarlo Romagnoni $\bullet$ and Antonio Stevan ^
}

\author{
* CNR-ITC, C.so Stati Uniti 4, 35127 Padova, Italy, paolo.bison@itc.cnr.it \\ - CNR-ISAC, C.so Stati Uniti 4, 35127 Padova, Italy \\ $\checkmark$ University IUAV of Venezia, S. Croce 191 - 30100 Venezia, Italy \\ ^SYNCRO srl, via Portello, 91 - 35129 Padova, Italy
}

\begin{abstract}
The Scrovegni Chapel in Padova (Italy) is worldwide renowned for the fresco cycle due to Giotto. The outstanding value of this work of art requires a continuous monitoring of its state of conservation. Starting from 1995 a Scientifictechnical Board coordinates the many initiatives and, among them, several measurement campaigns by IR thermography had been carried out. More recently, the hypogeal environments under the Chapel has been considered due to the presence of water which frequently submerges the floor and part of the vertical structures of the crypt. The present work reports on the activities and the results of those surveys.
\end{abstract}

\section{Introduction}

On $1300 \mathrm{AD}$, Enrico Scrovegni, who became rich by lending money, commissioned the building of a new chapel, presumably to atone for the sin of usury. He hired Giotto, the most recognized painter of the time, to decorate the inner walls of the chapel. Very little is known of the Chapel from the time when it was built and decorated, until 1881 when the municipality of Padova bought it in a state of decaying. Large restoration was done at the end of the XIX century and in the sixties of the last century. In 1995 a Scientific-technical Board settled down to coordinate the surveys of the conservation of the building structure and the preservation of frescos [1,2,3]. In the same year a systematic monitoring of the microclimatic variables began, together with the installation of a HVAC system to maintain temperature and humidity within acceptable ranges [4]. That was necessary to minimize the effects of the new dangerous appearance of the air pollution that appeared to be so harmful for the colours of the frescos. In 2002 the Chapel was reopened after being submitted to a new round of restoration and cleaning of the Giotto cycle by Istituto Centrale del Restauro. In 2016 a new plan was presented, focused on the Chapel Crypt (see Figure 1), whose floor is often affected by water sourcing from the ground. The new measurements campaign started in November 2017 and is still ongoing.

In and around the time of the last restoration, IR thermography was utilized successfully in the Chapel as a NonDestructive-Testing - Non-Contact technique, capable of revealing hidden structures, fresco detachment, cracks and humidity [5]. The results gave useful information to the restoration activities. It has been considered again in the frame of the new monitoring campaign of the Chapel Crypt, to identify the humidity rising on the walls and to evaluate if such humidity can reach the upper floor and affect the Giotto painting [6].

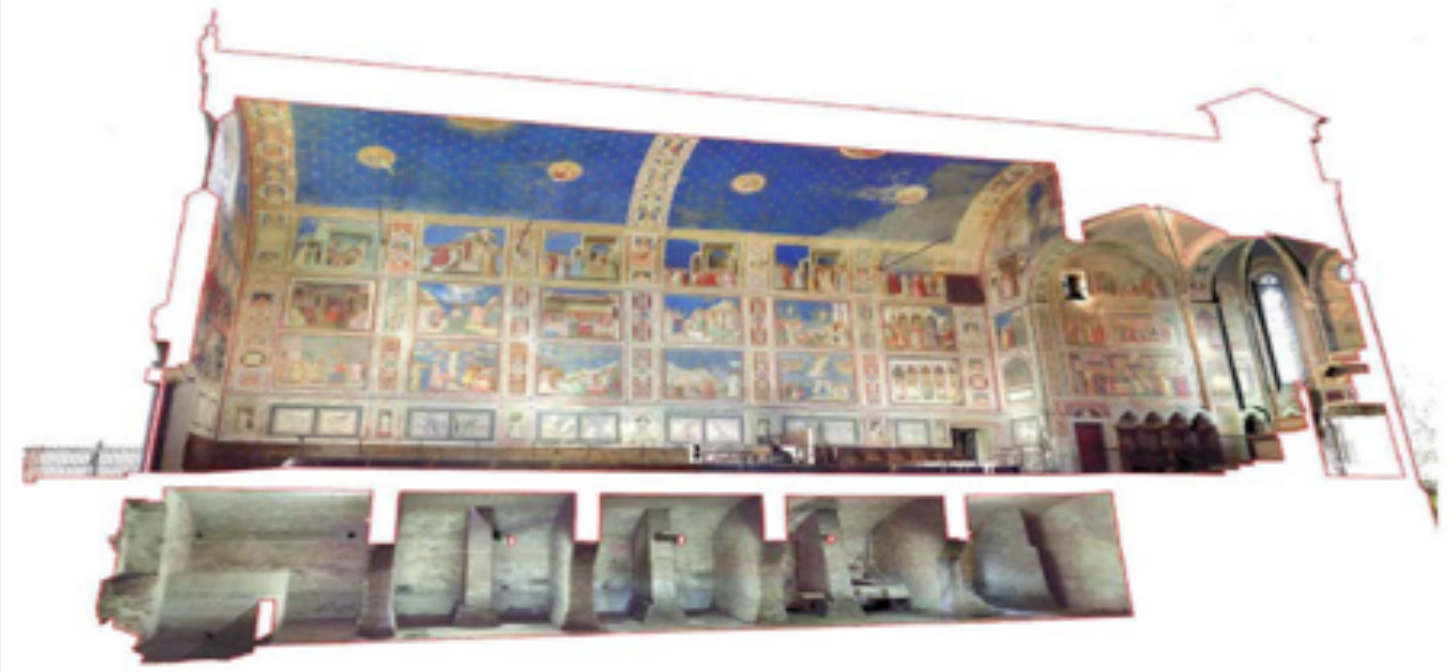

Fig. 1. The Scrovegni Chapel with the Crypt underneath. 


\section{IR thermography monitoring}

The main objective of the research is the identification of the degradation, if any, associated with the presence of water, that is present often in large quantities on the floor and part of the vertical structures of the crypt (perimeter walls and brick walls) springing from the floor itself, especially after rainy days, due to the raising of the groundwater level. The IR images have been collected during several campaign from winter 2017 and still ongoing.

All the thermographic acquisitions were conducted with a "passive" technique, that is, without the use of any thermal source or forced ventilation. From the IR images it is possible to see that the presence of water on the floor is not so high, after a pumping system was installed to drain the water in excess. On the other hand, the evaporative fronts, compatible with the presence of humidity inside the walls have been clearly identified (see example in Figure 2).

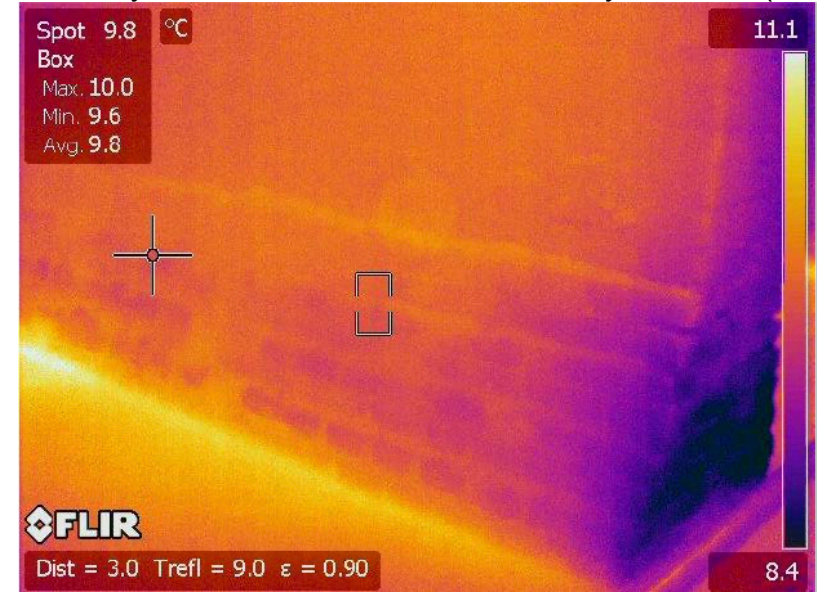

Fig. 2. IR image of the clay brick masonry that reinforce the Crypt vault over which the main hall of the Chapel is based.

\section{Conclusion}

Despite being underground, the Crypt is affected by a modest presence of water on the floor and it presents some evaporative fronts quite low on the reinforcing walls. The relative humidity of air was high during the analysed period but as an underground environment the values are not so impressive.

Further information can be obtained through the microclimate analysis still in progress and by a planned campaign of cyclic surveys using active thermographic techniques with the use of artificial forced ventilation in order to increase the evaporative effect of wet areas [7]. This technique improves identification and investigation of the relationship of the structures with the boundary conditions occurring as a result of seasonal thermo- hygrometric and seasonal changes or in relation to other exogenous phenomena related to the complex water system of the area on which the Scrovegni Chapel stands. In this way the hygrometric state of a surface is defined without resorting to gravimetric measures (invasive and destructive, such as the UNI 11085 standard), introducing a parameter called STI (Saturation Thermal Index), which allows to evaluate how much each point of the wall is close to or less than the saturation condition.

\section{REFERENCES}

[1] V. Fassina, Moisture problems inside the wall and facade protection (in Italian), Proceedings of the workshop "La Cappella degli Scrovegni - Indagini, restauri, interventi" - February 25th, Stampa Arti Grafiche Padovane, 37 $-41,1998$.

[2] M. Marabelli, Measurements and problems by pollutions and soluble salts (in Italian), Proceedings of the workshop "La Cappella degli Scrovegni - Indagini, restauri, interventi" - February 25th, Stampa Arti Grafiche Padovane, $48-53,1998$.

[3] C. Bonacina, P. Baggio, M. Mariotti, P. Romagnoni, Indoor microclimate management of the Scrovegni Chapel (in Italian), Proceedings of the workshop "La Cappella degli Scrovegni - Indagini, restauri, interventi" - February 25th, Stampa Arti Grafiche Padovane, 60 - 64,1998.

[4] C. Bonacina, P. Baggio, F. Cappelletti, P. Romagnoni, A.G. Stevan, The Scrovegni Chapel: The results of over 20 years of indoor climate monitoring, Energy and Buildings, 95, $144-152,2015$.

[5] E. Grinzato, C. Bressan, S. Marinetti, P.G. Bison, C. Bonacina. Monitoring of the Scrovegni Chapel by IR thermography: Giotto at infrared, Infrared Physics \& Technology, Volume 43, Issues 3-5, 165-169, 2002.

[6] Paolo Bison, Alessandro Bortolin, Gianluca Cadelano, Giovanni Ferrarini, Fabio Peron, Piercarlo Romagnoni and Antonio Stevan. Indoor monitoring of Scrovegni Chapel Crypt. CLIMA 2019, E3S Web of Conferences 111, 02075 (2019), https://doi.org/10.1051/e3sconf/201911102075

[7] P. Bison, G. Cadelano and E. Grinzato. Thermographic Signal Reconstruction with periodic temperature variation applied to moisture classification. QIRT Journal, 8(2), 2011. 